\title{
Motivating Unrewarded Task Performance: The Dual Effects of Incentives and an Organizational Value Statement in a Multitask Setting
}

\author{
Kazeem O. Akinyele \\ Assistant Professor \\ University of Wisconsin Oshkosh \\ 800 Algoma Blvd. \\ Oshkosh, WI 54901 \\ Email: akinyelk@uwosh.edu \\ Vicky Arnold \\ Professor II \\ NHH Norwegian School of Economics \\ and \\ Professor Emeritus of Accounting \\ University of Central Florida \\ Email: vicky.arnold@ucf.edu \\ Steve G. Sutton \\ Professor II \\ NHH Norwegian School of Economics \\ and \\ Professor Emeritus of Accounting \\ University of Central Florida \\ Email: steve.sutton@,nhh.no
}

Acknowledgements: We thank the University of Central Florida for providing financial support for this study. We would like to thank Weiming Liu for allowing us to use his z-Tree codes for the decoding task. We would also like to thank Theresa Libby, Khim Kelly, Yu Tian, Steve Salterio, Elizabeth Poziemski, Amy Donnelly, Jared Koreff, workshop participants at University of Central Florida, and participants at the 2020 Canadian Academic Accounting Association for their helpful comments. We thank Khim Kelly, Lisa Baudot, Rob Tennant, Nadra Pencle, Patricia Navarro Velez, Wioleta Olczak, Matt Holt, and University of Central Florida PhD students for help in pretesting the instruments and administering the experiments. Finally, we thank Adewale Obadimu for his valuable help in programming our experiments in z-Tree. 


\title{
Motivating Unrewarded Task Performance: The Dual Effects of Incentives and an Organizational Value Statement in a Multitask Setting
}

\begin{abstract}
Management control systems research increasingly recognizes the interactive effects of packages of controls. These interactive effects may be exacerbated in multitask settings consisting of both rewarded and unrewarded tasks. Organizational value statements are informal controls shown to alter the relationship between compensation schemes and performance. This study's purpose is to examine these value statement effects in a multitask environment consisting of both rewarded and unrewarded tasks. Results show that under fixed pay compensation, the presence of a value statement motivates performance on important but unrewarded tasks. Conversely, under piecerate incentive compensation, value statements negatively influence performance on unrewarded tasks. This study contributes to the management control literature by establishing how and when informal management control systems can improve employees' unrewarded task performance. In contemporary work environments where such multitask arrangements are common, the results suggest informal controls may be preferable to formal controls focused on incentive compensation.
\end{abstract}

Keywords: informal management control systems, incentive compensation schemes, organizational value statements, unrewarded task performance, social norm activation. 


\section{INTRODUCTION}

Contemporary management accounting research increasingly recognizes the interactive nature of management controls when considered as a package (Malmi and Brown 2008) such that informal controls may either sustain or circumvent formal controls (Norris and O'Dwyer 2004). The complexity of these packages of controls is heightened in multitask settings which are increasingly the norm (Christ, Sedatole, and Towry 2012b). Firms develop formal controls, often in the form of incentive contracts, to motivate employees to exert effort on certain tasks that are important to organizational success and to align employees' interests with those of the organization. Nonetheless, incentive contracts rarely govern all of the employees' responsibilities as management often cannot foresee all important tasks (Christ et al. 2012b) and effort on some tasks may be difficult or very expensive to measure (Christ, Emett, Summers, and Wood 2012a; Hecht, Tafkov, and Towry 2012). Extant research suggests informal controls, implicit structures adopted by management to align employees' actions with organizational goals, also play an important and complementary role in motivating employee effort (Berry, Coad, Harris, Otley, and Stringer 2009; Chenhall and Moers 2015). Informal controls that are congruent with formal controls can effectively integrate with financial incentives in a multitask setting to achieve performance objectives (Brüggen and Moers 2007); however, informal controls that are not in alignment on a given task may impede the viability of formal controls (Kachelmeier, Thornock, and Williamson 2016; Akinyele, Arnold, and Sutton 2020).

An organizational value statement is a commonly used informal management control (Kachelmeier et al. 2016) that guides the behaviors, attitudes, and character that management is trying to promote among employees (Highhouse, Hoffman, Greve, and Collins 2002; Urbany 2005; Wenstøp and Myrmel 2006; Akinyele et al. 2020). Hannan (2016) notes that value 
statements are ubiquitous in today's work environment. Kachelmeier et al. (2016) find that organizations can use quality-focused value statements along with incentive pay to direct employees' effort toward multiple task dimensions (i.e., quality of output and quantity of output), but that a focus on quality can dilute an intended focus on productivity. Akinyele et al. (2020) extend Kachelmeier et al. (2016) by examining the impact of a more general value statement on employees' performance. They find that similar effects occur with a more common generic value statement; and, the more salient the value statement, the greater the effect.

The purpose of this study is to extend the research on value statements as an informal control to better understand the interactive effects on formal controls in a multitask environment. Specifically, we extend the value statement literature by examining how the type of incentive scheme and the presence of a value statement reinforcing the importance of the employee's work to organizational success motivates employees to exert effort on an important, but unrewarded task. While Hecht et al. (2012) show that the influence of partial incentives ${ }^{1}$ on rewarded task performance spillovers to positively influence unrewarded task performance, our study considers how spillover effects are altered by packages of controls interacting. Prior research suggests that when employees are rewarded on multiple dimensions of the same task, they commit to multiple goals and divide their attention among those task dimensions (Brüggen and Moers 2007; Christ, Emett, Tayler, and Wood 2016). We extend this line of research by examining the joint effect of formal (incentive scheme) and informal (value statement) controls on employee performance related to an important but unrewarded task in a multitask environment.

We base our hypotheses on social norm activation theory (Bicchieri 2006), which posits that a social norm is activated when an individual becomes aware that a behavioral rule is

\footnotetext{
${ }^{1}$ Partial incentive contracts are contracts that provide performance-based pay for certain subset of the overall tasks (Hecht et al. 2012).
} 
relevant to the current social setting and develops normative expectations that follow the rule. Social norms can be applied to a situation where there is conflict between self-interest and prosocial incentives (Bicchieri 2006, 34). Conflict between self-interest and pro-social incentives arise when employees are not directly rewarded for a particular task (e.g., additional task, overtime). In the presence of a value statement promoting social belongingness, we expect that employees rewarded by fixed pay are more likely to exert effort and perform an unrewarded task than employees conditioned to being rewarded by performance-based pay (e.g., piece-rate incentive scheme) due to expectations that fixed pay employees will become more morally sensitive to the firm's performance objectives (Stevens and Thevarajan 2010; Stevens 2019). However, employees that are conditioned to being rewarded with piece-rate incentives are more likely to question the social belongingness espoused by a value statement, and may feel betrayed or cheated by the request to perform an unrewarded task. In short, we posit that a value statement promoting organizational belongingness will increase (decrease) task productivity for an unrewarded task in a multitask setting when prior tasks have been rewarded with a fixed pay (piece-rate) incentive. ${ }^{2}$ We also predict that the fixed pay group with a value statement present will outperform all other groups on an unrewarded task.

To examine our hypotheses, we conduct an experiment where participants assume the role of an employee in an organization. We test our hypotheses using a 2 (value statement present/absent) x 2 (incentive structure with fixed pay/piece-rate) between-subjects factorial design. Participants are undergraduate and graduate business students. They complete two effortsensitive laboratory tasks, a rewarded simple slider (primer) task and an unrewarded

\footnotetext{
${ }^{2}$ Productivity is defined as the quantity of output in this study. Since our experimental tasks are effort-sensitive, less productive implies less output, and more productive implies more output.
} 
computerized decoding task. Our dependent variable is participants' performance on the unrewarded task measured as quantity of symbols decoded in the unrewarded task.

As predicted, fixed pay participants with a value statement perform significantly better on the unrewarded task than piece-rate participants (with or without a value statement) and fixedpay participants without a value statement. Moreover, we also observe a similar disordinal interaction to that observed in Kachelmeier et al. (2016) and Akinyele et al. (2020) when considering the interactive effects of formal (incentive) and informal (value statement) controls. This result is consistent with the proposition that employees operating under fixed pay are more receptive to the social belongingness promoted by a value statement, a behavior consistent with normative expectations being activated by social norms (Bicchieri 2006; Blay, Gooden, Mellon and Stevens 2018; Akinyele et al. 2020). This result extends the findings from Kachelmeier et al. (2016) and Akinyele et al. (2020) by showing additional benefits of a value statement as an informal management control in multitask settings (Hecht et al. 2012), while also highlighting the less desirable performance outcomes exuding from mixing piece-rate incentives with a value statement promoting social belongingness (Akinyele et al. 2020).

This study contributes to both research and practice. First, this study extends prior research on the effects of incentives on performance spillover in a multitask setting. Specifically, our study highlights the effect of alternative types of incentives on unrewarded task performance. This research directly addresses Hecht et al.'s (2012) call for future research to further explore antecedents and consequents of the spillover effect, as they view their study as just scratching the surface in terms of understanding the effect of management controls in multitask settings. While Hecht et al. (2012) show the influence of partial incentives on rewarded task performance spillover to positively influence unrewarded tasks, this study shows that the overall package of 
controls that may be present in multitask settings can substantially alter these effects. The complexity of multitask settings with partial incentives becomes even more complex in the presence of informal controls that may not necessarily be consistent in their performance motivating effects.

Second, our study contributes to management accounting multitask literature through the use of two different tasks in our experiment. We use a rewarded slider task to prime participants, and follow up with an unrewarded decoding task. Both tasks are effort-based and are significantly different from each other. Hecht et al. (2012) highlight that the tasks they use in their study are too similar in terms of the processes required to complete them, hence the degree to which spillover occurs in their study may be a function of task similarity. They suggest that future research should use different tasks in the same experiment to explore multitask behavior. Our study directly addresses this call for future research with the use of distinctive tasks in this multitask study.

Third, despite the benefits noted in prior literature (Bonner and Sprinkle 2002; Cianci, Kaplan, and Samuels 2013; Libby and Lipe 1992), this study highlights a situation where piecerate compensation may result in a less productive outcome (Lepper and Greene 1978). Specifically, our study demonstrates that when the multitask nature of contemporary business environments (Christ et al. 2012b) are considered and when these tasks can only be partially incentivized due to difficulty or cost of measuring some tasks performance (Christ et al., 2012a; Hecht et al. 2012), the predictability of incentive scheme driven behavior wanes. This complexity of the business environment necessitates a reconsideration of the mix of formal and informal controls that should be used to motivate employee performance. For unrewarded tasks, informal controls oriented toward social belongingness (Bicchieri 2006) can actually motivate 
employee effort and performance more than formal controls; but, when both are present, the outcome may be even more negative. This study directly contributes to the conversation on the effect of incentives in multitask principal-agent analyses by introducing social $/$ moral norms (Holmstrom and Milgrom 1991; Stevens and Thevaranjan 2010; Blay et al. 2018). This contribution is particularly relevant to organizations that pay fixed salaries, as it shows that management can implement a value statement that provides moral sensitivity to motivate employees and improve productivity; providing additional economic incentives is not the only way (nor necessarily the best way) to motivate employees' overall performance. At the same time, this research also addresses a void in the empirical research on how situational factors alter the adoption of social norms (Bicchieri 2006, 63).

Fourth, this study contributes to the literature by highlighting how value statements can alter employees' productivity. Prior research investigates the role of financial incentives and social incentives in multitask settings (Brüggen and Moers 2007). While prior research focuses on social incentives which are non-economic factors that seem to play an important role in a modern work environment where employees work together in groups or teams (Brüggen and Moers 2007), our study specifically focuses on a value statement which is a very common form of informal management control (Berry et al. 2009; Kachelmeier et al. 2016). Kachelmeier et al. (2016) and Akinyele et al. (2020) have examined the effects of value statements as a form of informal management control in accounting. While their studies show that both a qualityoriented and a general value statement can lower productivity under piece-rate compensation, our study highlights further complexities from the interaction of these formal and informal control systems when considered in a multitask setting. The value statement can complement the role of economic incentives when those incentives do not apply directly to employees' important 
and new responsibilities by creating social/moral responsibilities that can positively influence employees' self-interest (Stevens and Thevaranjan 2010; Blay et al. 2018). The presence of a value statement, when not in conflict with their prior organizational beliefs, will consciously or subconsciously encourage employees to internalize the organization's values, which encourages them to be better organizational citizens by taking on tasks that help the organization, but for which they are not directly rewarded (Smith, Organ, and Near 1983). Understanding what makes people focus on particular norms, how this is altered by conflicting norms, and how sensitive norms are to situational factors is of great practical importance (Bicchieri 2006, 63).

The paper proceeds as follows: The next section discusses the background literature and hypotheses development. This is followed by sections that discuss the experimental method and design, the results, and finally, the conclusion and opportunity for future research.

\section{BACKGROUND AND HYPOTHESES}

\section{Value Statements as a Form of Informal Control}

Informal management controls are used to shape employee behavior in a manner that is consistent with overall organizational goals (Berry et al. 2009). These controls are labelled informal, as they are not linked directly to the formal compensation and reward systems. Examples of informal controls that have been examined in prior accounting studies include social norms such as honesty and reciprocity (Tayler and Bloomfield 2011), a strong organizational culture (Chow, Harrison, McKinnon, and Wu 2002; Dent 1991; Henri 2006; Pratt and Beaulieu 1992) and value statements (Kachelmeier et al. 2016; Akinyele et al. 2020). We extend this line of research by examining the impact of a value statement on employee behavior in a multitask setting. A value statement defines the behaviors, attitudes, and character that management is trying to promote among an organization's employees (Highhouse et al. 2002; 
Urbany 2005; Wenstøp and Myrmel 2006), and is intended to guide everyday decisions and help to clarify what is expected from employees (Urbany 2005).

Prior research in management has examined the use of value statements to exert social pressure on employees within an organization without explicit measures to enforce that pressure (O'Reilly III, Chatman, and Caldwell 1991). Kachelmeier et al. (2016) bring the value statement discourse into the accounting literature as an informal control that can interact with formal controls. Their results show that a value statement that emphasizes production quality, when combined with an incentive contract that compensates employees for production quantity, reduces productivity. This result presumably occurs because employees divide their effort between increasing quantity of output and ensuring products produced are of high quality, even though the value statement is completely redundant with the incentives (Hannan 2016).

Akinyele et al. (2020) revisit the Kachelmeier et al. (2016) findings and consider how a more general value statement that emphasizes organizational belongingness interacts with formal controls (incentives). Akinyele et al. (2020) find a similar interaction effect to the findings of Kachelmeier et al. (2016). These findings raise additional questions within the context of the emerging research on multitask settings where it is difficult to economically incentivize all tasks, there is a high probability that both formal and informal controls will be present, and the duality of the control processes will interact in ways that may not be intended (Malmi and Brown 2008).

\section{Impact of Incentives for Rewarded Tasks on Unrewarded Task Performance}

In a multitask setting, employees may be directly rewarded for some tasks but not for others. For example, employees may be directly rewarded for productivity but may also be expected to complete other tasks for which they are not rewarded, such as mentoring junior 
employees. In such situations, organizations invariably strive to create a culture that fosters such mentoring behavior and other behaviors that lead to enhanced organizational performance.

Accounting researchers have begun to investigate the interactive effect of management control systems that combine both financial incentives (formal controls) and social incentives (informal controls) in multitask settings where the agent must make multiple effort choices. Brïggen and Moers (2007) find that in multitask settings effort choices of the agent consist of both an effort level choice and effort allocation choice, and that different compensation schemes have different effects on these effort choices. They suggest that despite the benefits of piece-rate financial incentives in increasing effort level, fixed pay incentives have greater benefit in aligning effort allocation with the principal's interest (although at decreased effort levels) (Brüggen and Moers 2007). While it is important to have increased effort level choice with the use of financial incentives, Brüggen and Moers (2007) conclude that social incentives can have a decision influencing role on the effectiveness of financial incentives. Based on their preliminary findings, they suggest that future studies need to further explore the interactive effect of social and financial incentives, as their study used social incentives that were punitive in nature, focusing on the embarrassment of admitting that one deviates from social norms (Brüggen and Moers 2007).

Hecht et al. (2012) consider the environments that likely have such mixed incentive schemes by focusing on the effect of different types of incentive schemes on specific rewarded task performance, and then considering the spillover effects to unrewarded tasks. They focus on how the use of sequential versus simultaneous task performance can affect the spillover effects under alternative incentive schemes. They suggest that relative to a fixed pay scheme, partial incentives that compensate productivity on some tasks, but not on other important tasks, increase 
the disparity in effort allocation toward rewarded versus unrewarded tasks (Hecht et al. 2012). Specifically, they show that partial incentives decrease unrewarded task performance when the tasks are performed sequentially, but not when the task are performed simultaneously (Hecht et al. 2012). The implication is that, depending on the structure and nature of the assigned tasks, performance based incentives may have varying effects on task performance in multitask settings. Hecht et al. (2012) conclude that the negative effect of performance based incentives can be partially mitigated by a spillover effect.

Prior research indicates that piece-rate pay motivates higher effort and performance than fixed pay on effort-sensitive tasks when the tasks are considered in isolation (Sprinkle 2000; Bonner and Sprinkle 2002). Yet, research also suggests that in some situations, piece-rate pay does not improve, and sometimes even degrades, performance (Fessler 2003; Ashton 1990). For example, Frey and Jegen (2001) argue that piece-rate incentives undermine self-regulation, making it difficult for employees to take responsibility for a task that is not directly rewarded. Similarly, Stevens and Thevaranjan (2010) show that when morally sensitive information is integrated into a task, fixed pay employees' productivity increases. Blay et al. (2018) suggest that future research on incentive systems should focus on both organizational and individual factors to better understand how formal controls affect behavior within a given social context. Blay et al. (2018) argue specifically that application of social norm activation theory (Bicchieri 2006) could enrich management accounting's understanding of how organizational context alters incentive systems' effect on employee behavior.

Bicchieri (2006) highlights how social norms are activated as individuals become aware that a behavioral rule is relevant to the current social setting, and social norm activation leads individuals to develop normative expectations that follow the rule. Social norms can be formal or 
informal, personal or collective, descriptive or prescriptive of behavioral rules that determine right versus wrong in a given setting. Social norms evolve in ways that depend on an individual's psychological disposition, and are shared beliefs that must be examined from the perspective of both the individual's psychological system and the general organizational settings in which the individual operates (Blay et al. 2018; Stevens 2019).

In accounting, experimental researchers have found social norm activation theory to be relevant in explaining principal-agent relationships and the implications for overall firm productivity. For example, Stevens and Thevaranjan (2010) use insights from Bicchieri (2006) to propose a moral solution to a moral hazard problem. Specifically, they suggest that it is appropriate for the principal to pay the agent the first-best salary in exchange for the first-best effort, provided the agent is morally sensitive to the firm's productivity. They establish that for fixed pay contracts, adding moral sensitivity increases the descriptive power of the principalagent model (Stevens and Thevaranjan 2010). Similarly, Akinyele et al. (2020) show how and why a value statement inducing sensitivity to social norms alters the effects of incentives on performance; a contemporary value statement promoting organizational belongingness increases (decreases) productivity associated with fixed pay (piece-rate) incentives.

A complete contract that incentivizes all relevant aspects of an employee's performance is ideal; however, it may not be economically feasible in many situations (Choi, Hecht, Tafkov, and Towry 2016). Thus, motivating employees to perform tasks for which they are not directly rewarded is in the best interest of the organization. Organizations need employees who take the initiative to make decisions that benefit organizations. The most valuable employees may not be those that perform better with incentives; rather, they may be those that are willing to help their organizations whenever the need arises, with or without direct incentives (Robinson, Kraatz, and 
Rousseau 1994). It may not be ideal for employees to see monetary incentives as the main motivation to perform their responsibilities, but they may see monetary incentives as an appreciation for performing their responsibilities to the best of their abilities.

Organizations use incentive schemes to encourage employees to perform consistent with organizational goals (Bonner, Hastic, Sprinkle, and Young 2000; Bonner and Sprinkle 2002). Despite the benefits of piece-rate over fixed pay incentive schemes on effort-sensitive tasks (Bonner et al. 2000), our study proposes that there are certain situations where fixed pay may be more beneficial. Specifically, our study proposes that when employees are not directly rewarded for performing a task, employees operating under a fixed pay incentive scheme will be positively influenced by a value statement that promotes organizational belongingness (Akinyele et al. 2020). The belongingness promoted by the value statement should help induce a moral sensitivity to the firm's productivity (Stevens and Thevarajan 2010; Blay et al. 2018).

On the other hand, employees rewarded with piece-rate incentives will be less motivated by the value statement than those operating under a fixed pay scheme since piece-rate provides direct incentives for creation of output on the rewarded task which creates a norm of pay being linked to the value of the employee. A value statement that counters this norm by telling employees they are valued even when performance pay is withdrawn creates an incongruence with the expectations formulated through the reward structure. As Bicchieri $(2006,79)$ notes, priming a norm is not a simple process, and employees need to be able to focus on the norm. There must be enough cues in the environment to reinforce the norm, but conflicting cues pointing to different norms can lead to rejection of the norm. In our situation, an employee is more likely to meet the value statement with skepticism and feel deceived by the organization when performance pay is withdrawn, but effort is still expected. This dissidence is unlikely to 
lead to an increase in moral sensitivity to organizational performance and is more likely to create a negative perception of belongingness. As Bicchieri (2006, 56-57) notes, particular preferences and beliefs are not always activated as desired, but rather an employee's beliefs are an interpretation of the surrounding environmental cues.

In combination, these effects suggest that the disordinal interaction observed by Kachelmeier et al. (2016) and Akinyele et al. (2020) on rewarded tasks considered in isolation should be present in the spillover effects on an unrewarded task in a multitask environment. An agent (employee) will have a conditional preference for conforming to the norm embodied by the value statement (Bicchieri 2006, 57). This leads to the following hypothesis:

H1: A value statement promoting organizational belongingness will increase (decrease) task productivity for an unrewarded task in a multitask setting when prior tasks have been rewarded with a fixed pay (piece-rate) incentive.

Prior research in multitask environments provide evidence of a spillover effect between rewarded and unrewarded tasks. While piece-rate individuals put more effort into rewarded tasks, the performance levels on unrewarded tasks were still at levels consistent with effort by other unrewarded individuals (Hecht et al. 2012). However, a value statement has been shown to have positive effects on the performance of fixed pay rewarded employees (Akinyele et al. 2020). This is consistent with the establishment of a social norm that promotes behavior congruent with the organization's objectives regardless of the personal effort required (Bicchieri 2006; Stevens and Thevaranjan 2010; Blay et al. 2018; Stevens 2019). If this social norm takes hold during a rewarded task in a fixed pay arrangement, the social norm should not be conflicted with the unrewarded task, and would be expected to spillover during task completion. Thus, employees in a multitask environment rewarded with fixed pay are expected to have enhanced 
levels of performance on both rewarded and unrewarded tasks, as motivated through the value statement. This leads to the second hypothesis:

H2: A value statement promoting organizational belongingness combined with a fixed pay incentive in prior tasks will lead to the highest productivity level for an unrewarded task in a multitask setting.

\section{RESEARCH METHOD}

\section{Experimental Design and Procedures}

This study utilizes a $2 \times 2$ between-participants experimental design that manipulates incentive (fixed pay vs. piece-rate) and value statement (present vs. absent). Participants are provided a hypothetical case about a company and asked to perform two different tasks—a rewarded slider task in Phase 1 and an unrewarded decoding task in Phase $2^{3}$. The purpose of Phase 1 is to prime participants relative to the incentive scheme and the value statement, if present. The purpose of the Phase 2 task is to examine whether the different types of incentive scheme impact participants' performance when asked to voluntarily complete an unrewarded task and whether that performance differs when a value statement is present. We used two different tasks to differentiate the rewarded task from the unrewarded task. Participants complete both tasks in a laboratory setting using z-Tree software (Fischbacher 2007). See Figure 1 for a summary of the experimental procedures.

\section{[Insert Figure 1 here]}

The opening screen presents the informed consent and overviews the experiment.

Individuals who agree to participate proceed to the second screen which informs participants that they will read important information, followed by comprehension check questions to assess their understanding of the material. Participants then proceed to Phase 1 in which they read

\footnotetext{
${ }^{3}$ The slider task is adapted from Gill and Prowse $(2011,2012)$. The decoding task is adapted from Liu (2017).
} 
background information about a hypothetical corporation, instructions for completing the primer task, the details of their incentive scheme, and information about the value statement (for those in the value statement present condition). Participants must correctly answer comprehension checks before proceeding to the primer task. After completing the primer task, participants receive a performance report stating their actual earnings.

In Phase 2, the experimental task, participants are asked to complete a second task at the request of the CEO, which will take about five minutes. Participants are specifically told that their reward for participating will remain unchanged regardless of their performance on the Phase 2 task. Participants then receive instructions for the unrewarded decoding task and answer additional comprehension check questions to ensure that they understand they will earn no additional rewards for completing the task. Participants must answer this question correctly before they are able to proceed to the next screen. After completing the unrewarded task, participants then respond to manipulation check and demographic questions.

\section{Phase 1 - Primer Task}

In Phase 1, participants are asked to complete a rewarded task which is used to prime participants as to the type of incentive scheme. Participants are presented with background information for a hypothetical scenario in which they assume the role of an employee of the company. Employees are responsible for adjusting sliders, an important piece of automation equipment, between 0 and 100 with the use of their mouse only; each slider must be correctly positioned at 50. Participants perform one 60 -second practice round and four 120 -second paid rounds. In each round, participants move as many sliders as possible up to a maximum of 48 , and score points for the number of sliders correctly positioned. The score, along with the time 
remaining in the round, is shown at the top of the screen. After each paid round, participants see their results before moving to the next round.

In this study, we use an experimental currency called "Lira." Participants in the fixed pay incentive condition receive 240,000 Lira, while participants in the piece-rate incentive condition receive 3,000 Lira for each slider they correctly position at 50. We set the piece-rate at 3,000 Lira for each slider correctly positioned based on the pretest results to ensure that participants in the piece-rate condition earn about the same amount as those in the fixed pay condition. For every 30,000 Lira earned, participants receive $\$ 1$, which is paid in cash at the end of the experiment. The average payment was $\$ 7.69$ per participant for about 30 minutes of their time. ${ }^{4}$ Half of the participants are randomly assigned to the treatment condition with the value statement, and the remaining half are randomly assigned to the treatment condition without the value statement. The value statement manipulation is the same as that used in Akinyele et al. (2020) and worded as follows: "Before completing your decoding task, the CEO would like to remind you of the KS Upright value statement, which emphasizes that: The work YOU do is an important part of the success of our company. Together we build systems that work!" (emphasis as in the original).

\section{Phase 2 - Unrewarded Decoding Task}

In Phase 2, participants are asked to complete a different task (a decoding task) for which they are not be rewarded to see whether the effects of incentive scheme and value statement

\footnotetext{
${ }^{4} \mathrm{~A}$ third incentive condition was included in the original experiment in which participants were paid under a quota incentive, that is, a fixed payment of 45,000 Lira per round plus a piece-rate of 1,500 Lira for every slider correctly positioned after the first 10 in each round. Forty-two participants completed the experiment in this condition. Participants appear to have treated this condition similarly to the piece-rate condition (i.e., they ignored the fixed pay), but it is difficult to say exactly how much weight they placed on each part of the incentive contract. Therefore, for simplicity's sake, we test for differences between the piece-rate and fixed pay participants as these conditions allow for a more direct test of our hypotheses.
} 
spillover into their unrewarded task performance ${ }^{5}$. In the decoding task, participants are instructed to use the keys provided on the left side of the screen to correctly identify the number associated with the letter from the alphabet shown on their screen. For each number recorded correctly, they receive a point score that is shown on the screen. If the number is incorrect, they get an error message; but, they have unlimited attempts to get the correct number. The time that they have remaining in any given round is shown in the upper right-hand corner of their screen, while the total number of alphabets correctly decoded in each round is shown at the center of the screen. They have 30 seconds for one practice round, and 60 seconds for four working rounds. Before starting the unrewarded task, participants in the value statement present condition again see the value statement.

\section{Variables}

The focus of this study is employees' unrewarded task performance in Phase 2; hence, the main dependent variable of interest is the number of letters that the participants decode in the unrewarded task. Participants complete four working rounds of the decoding task, and the total number of letters decoded during the four rounds is the dependent variable for hypotheses testing. In order to examine the spillover effects on performance of an unrewarded task, the two treatments, type of incentive and presence or absence of a value statement, from the Phase 1 task are the independent variables.

\section{Participants}

Eighty-eight graduate and undergraduate business students participate in the experiment. Fifty-one percent of the participants are male and forty-nine percent are female. Most

\footnotetext{
${ }^{5}$ We specifically informed the participants that they will not be paid for completing this exercise since their paid exercise has already been completed. We also informed them that their performance in this decoding task is important, but their "compensation will remain unchanged" regardless of their performance in this decoding task.
} 
participants are between 21-25 years old (52 percent) and have 1-5 years of work experience (64 percent). Eighty-eight percent of participants are undergraduate accounting majors in their junior or senior year.

\section{RESULTS}

\section{Primer Task}

Participants spent approximately 30 minutes completing the primer task which was an effort intensive task related to moving sliders into a precise position. ${ }^{6}$ Using a generic value statement focused on organizational belongingness, the performance effects are very similar to those found in Kachelmeier et al.'s (2016) study using a value statement emphasizing quality (see Figure 2). Thus, performance on the primer tasks fit the pattern expected suggesting participants are behaving normally in the first part of the multitask experiment. Participants were subsequently asked to perform a completely different effort intensive task that was unrewarded and required an additional five minutes of effort. The unrewarded task is used to test the hypotheses related to spillover effects in a multitask setting.

[Insert Figure 2 here]

\section{Descriptive Statistics}

Table 1 Panel A presents descriptive statistics for unrewarded task performance across the four treatment conditions. In the fixed pay condition, the mean (standard deviation) of unrewarded decoding task performance is 95.60 letters decoded (16.90) when the value statement is absent but improves to 117.71 letters decoded (24.61) when the value statement is present. In the piece-rate incentive pay condition, the mean (standard deviation) of unrewarded task performance is 107.83 letters decoded (18.42) when the value statement is absent but goes

\footnotetext{
${ }^{6}$ See Akinyele et al. (2020) for greater detail on the slider task and behavioral patterns under fixed pay and piecerate incentive both with and without a value statement.
} 
down to 95.10 letters decoded (15.57) when the value statement is present. Means by condition are depicted graphically in Figure 3.

[Insert Figure 3 and Table 1 here]

\section{Tests of Hypotheses}

To test our hypothesis, we conduct an ANOVA with unrewarded task performance as the dependent variable. Results indicate a significant interaction between the presence/absence of a value statement and incentive on unrewarded task performance $\left(\mathrm{F}_{1,84}=17.61, \mathrm{p}<0.001\right.$, twotailed) and the graphical depiction of these results in Figure 3 indicates that the interaction is disordinal as hypothesized. Thus, H1 is supported.

H1 predicts both a decreasing effect on piece-rate performance from a value statement, and an increasing effect on fixed pay performance from a value statement during completion of an unrewarded task. Accordingly, we also examine the simple effects for the piece-rate incentive and fixed pay groups to better understand the role of each effect on the significance of $\mathrm{H} 1$.

Examining the piece-rate incentive condition under the two value statement conditions (presence/absence), unrewarded task performance is significantly lower $\left(\mathrm{F}_{1,84}=4.72, \mathrm{p}=0.033\right.$, one-tailed) when the value statement is present (95.10) than when it is absent (107.83). These results support the hypothesized diminution effect on piece-rate performance from the presence of a value statement and further support $\mathrm{H} 1$.

Similarly, we examine the fixed pay condition under the two value statement conditions (presence/absence). Simple effects presented in Table 1 (Panel C) further indicate that in the fixed pay condition, unrewarded task performance when value statement is present (117.71) is significantly higher $\left(\mathrm{F}_{1,84}=14.14, \mathrm{p}<0.001\right.$, one-tailed $)$ than when the value statement is absent (95.60). These results support the hypothesized enhancement effect on fixed pay performance 
from the presence of a value statement and further support H1. Hence, $\mathrm{H} 1$ is strongly supported with the overall significant disordinal interaction, and both the hypothesized diminutive effect of a value statement on piece-rate performance and the enhancing effect on fixed pay all being significant for unrewarded task performance.

$\mathrm{H} 2$ focuses more specifically on the fixed pay condition in the presence of a value statement on an unrewarded task. Our theorizations predict that a fixed pay scheme in the presence of a value statement emphasizing organizational belongingness will provide greater motivation to perform on an unrewarded task than under any of the other conditions. Per Buckless and Ravenscroft (1990), we set the contrast weights at 3 for the fixed pay with value statement condition and at -1 for the three other conditions. The results, shown in Table 1 (Panel D), support H2 ( $\mathrm{t}=3.34, \mathrm{p}=0.002)$.

\section{Additional Analysis}

As noted earlier, we have a very limited understanding of how spillover effects into unrewarded tasks are affected by various incentive schemes. Our understanding of the persistence of these effects are likewise generally void in the research. To shed light on the persistence of our experimental findings, we compared the performance on the first two rounds versus the last two rounds to consider whether the experimental findings diminished over time.

Tables 2 and 3 present the descriptive data broken out into the first two rounds and the last two rounds. The descriptive results reflect that all of the groups improved performance in the latter two rounds which is consistent with a positive learning effect as opposed to a diminishing spillover effect. While there are small learning effects exhibited in three of the groups, we see that the fixed pay group with a value statement exhibits even greater learning effects consistent with greater motivation to perform and stronger spillover effects. 
[Insert Tables 2 and 3 here]

\section{DISCUSSION}

This study examines the effect of a value statement in a multitask environment on unrewarded task performance. Prior literature highlights that incentive contracts cannot completely govern all employees' responsibilities (Christ et al. 2012b). Using economic incentives to explicitly stimulate all expected behavior is desirable, but it is very difficult to achieve (Choi et al. 2016). In multitask environments where there are both rewarded and unrewarded tasks, it is important to examine how organizations can use informal management control systems such as value statements to complement economic incentives in order to ensure that employees exert effort to perform unrewarded tasks. This study draws upon social norm activation theory, which proposes that a social norm is activated when employees become aware that a behavioral rule is relevant to the current social setting and such employees develop normative expectation that follow the rule (Bicchieri 2006; Stevens 2019). We predict that employees motivated by a value statement and incentivized by fixed pay are more likely to exert higher levels of effort to perform unrewarded tasks than employees incentivized by performancebased pay because fixed pay employee are more likely to develop normative expectation toward the unrewarded tasks than piece-rate employees. Employees who find their piece-rate incentives withdrawn experience a dissonance with the value statement that limits their feelings of belongingness and inhibits adoption of desired social norms.

As predicted, we find a negative effect of a value statement on piece-rate incentivized workers' effort and performance on an unrewarded task in a multitask setting. Also as predicted, we find a positive effect of a value statement on fixed pay incentivized workers' effort and performance on the unrewarded task. As expected, the spillover effects from the rewarded task to 
the unrewarded task are greatest when rewarded activities are incentivized with fixed pay and there is a value statement present that emphasizes importance and belongingness to the organization. Fixed pay compensation coupled with a value statement leads to the highest levels of effort and performance for the unrewarded tasks.

Further analysis of unrewarded task performance over time (first two rounds versus last two rounds) shows that spillover effects on performance persist for all groups with apparent learning effects present. However, consistent with the strong motivation hypothesized for the fixed pay group with a value statement, the effort and perceived learning effects were greatest among this group.

Similar to Kachelmeier et al. (2016) and Akinyele et al. (2020) findings for rewarded task performance, we find a disordinal interaction between compensation scheme and the presence of a value statement on our unrewarded task. However, as expected, there is a much stronger effect for the spillover effects from a rewarded task to an unrewarded task. The implication of this finding is that a value statement may be the most effective means to promote overall performance when there are both rewarded and unrewarded tasks present in the work environment. This has the added benefit of also promoting organizational belongingness among employees, which is considered positive for work environments (Bicchieri 2006).

Organizations invest in the creation and dissemination of value statements in order to manage external impressions and reputation (Urbany 2005); however, they often pay little or no attention to improving internal productivity with the use of value statements (Highhouse et al. 2002). If an organization values all the information included in their value statement, then they could make an effort to effectively communicate their values to their employees, especially employees that receive fixed pay compensation. This may encourage employees to consciously 
or subconsciously embrace the promoted values and accept the values as social norms (Bicchieri 2006). Value statements are believed to provide clarity to expectations from employees when effectively implemented.

This study contributes to the literature in several important ways. First, the study extends the contributions of Kachelmeier et al. (2016) and Akinyele et al. (2020) by examining the effect of nonbinding value statements on employees' performance in an important but unrewarded task in a multitask setting. This study is important as it is the first study that specifically examines the effect of the type of incentive structure and the interaction among control structures on employees' performance on unrewarded tasks. Technology has drastically influenced the way organizations maintain their competitive advantage; hence, organizations need to recruit and retain employees that believe in the values of the organization as it is very difficult to incentivize all aspects of employees' responsibilities (Choi et al 2016). Investigating the reactions of employees under different incentive structures to perform unrewarded tasks provides a unique contribution to the managerial accounting literature.

Our study is distinctly different from prior research on value statements in several ways. First, our study focuses on a multitask setting, while Akinyele et al. (2020) focus on the wording and saliency of value statements in a single task setting. Second, our study focuses on unrewarded task performance while Akinyele et al. (2020) focus on rewarded task performance. Third, our study uses a value statement that emphasizes the importance of employees to the organization while Kachelmeier et al. (2016) use a narrower, quality-focused value statement to examine employees' performance on one task with a mix of dimensions (Hannan 2016). Fourth, our study provides additional insight on the influence of value statement induced social norms on 
economic behavior (Bicchieri 2006, 105; Blay et al. 2018; Stevens 2019), highlighting the interactive effects of norms on incentive compensation schemes in complex work arrangements.

Our results suggest several avenues for future research. First, we use a laboratory experiment for this study; future research in the form of field experiments may help our understanding of additional practical implications of the findings. Second, we use student participants in our study. Using actual employees in future research could make incentives more salient. Notwithstanding its limitations, this study extends the literature on the usefulness of informal management controls by establishing the type of incentive that results in employees' productive performance on unrewarded tasks. Finally, the study supports Kachelmeier et al. (2016) and Akinyele et al. (2020) by reinforcing the importance of nonbinding value statements under different incentive structures. 


\section{References}

Akinyele, K., V. Arnold, and S.G. Sutton. 2020. Wording and saliency matter: The impact of incentive systems and organizational value statement on employees' performance. Behavioral Research in Accounting 32 (1): 101-118.

Ashton, R. H. 1990. Pressure and performance in accounting decision settings - Paradoxical effects of incentives, feedback, and justification. Journal of Accounting Research 28: 148180.

Berry, A., A. Coad, E. Harris, D. Otley, and C. Stringer. 2009. Emerging themes in management control: A review of recent literature. British Accounting Review 41 (1): 2-20.

Bicchieri, C. 2006. The Grammar of Society: The Nature and Dynamics of Social Norms. New York: Cambridge University Press.

Blay, A., E. Gooden, M. Mellon, and D. Stevens. 2018. The usefulness of social norm theory in empirical business ethics research: A review and suggestions for future research. Journal of Business Ethics 152 (1): 191-206.

Bonner, S., R. Hastie, G. Sprinkle, and S. Young. 2000. A review of the effects of financial incentives on performance in laboratory tasks: Implications for management accounting. Journal of Management Accounting Research 12 (1): 19-64.

Bonner, S., and G. Sprinkle. 2002. The effects of monetary incentives on effort and task performance: Theories, evidence, and a framework for research. Accounting, Organizations and Society 27 (4-5): 303-345.

Brüggen, A., and F. Moers. 2007. The role of financial incentives and social incentives in multitask settings. Journal of Management Accounting Research 19 (1): 25-50.

Buckless, F. A., and S. P. Ravenscroft. 1990. Contrast coding: A refinement of ANOVA in behavioral analysis. The Accounting Review 65 (4): 933-945.

Chenhall, R., and F. Moers. 2015. The role of innovation in the evolution of management accounting and its integration into management control. Accounting, Organizations and Society 47: 1-13.

Choi, J., G. Hecht, I. Tafkov, and K. Towry. 2016. Vicarious learning under implicit contracts. Accounting Review 91 (4): 1087-1108.

Chow, C., G. Harrison, J. McKinnon, and A. Wu. 2002. The organizational culture of public accounting firms: Evidence from Taiwanese local and US affiliated firms. Accounting, Organizations and Society 27 (4-5): 347-360.

Christ, M., S. Emett, S. Summers, and D. Wood. 2012a. The effects of preventive and detective controls on employee performance and motivation. Contemporary Accounting Research 29 


\section{(2): $432-452$.}

Christ, M., S. Emett, W. Tayler, and D. Wood. 2016. Compensation or feedback: Motivating performance in multidimensional tasks. Accounting, Organizations and Society 50: 27-40.

Christ, M., K. Sedatole, and K. Towry. 2012b. Sticks and carrots: The effect of contract frame on effort in incomplete contracts. Accounting Review 87 (6): 1913-1938.

Cianci, A., S. Kaplan, and J. Samuels. 2013. The moderating effects of the incentive system and performance measure on managers' and their superiors' expectations about the manager's effort. Behavioral Research in Accounting 25 (1): 115-134.

Dent, J. 1991. Accounting and organizational cultures: A field study of the emergence of a new organizational reality. Accounting, Organizations and Society 16 (8): 705-732.

Fessler, N. 2003. Experimental evidence on the links among monetaryincentives, task attractiveness, and task performance. Journal of Management Accounting Research 15 (1): $161-176$.

Fischbacher, U. 2007. z-Tree: Zurich toolbox for ready-made economic experiments. Experimental Economics 10 (2): 171-178.

Frey, B., and R. Jegen. 2001. Motivation crowding theory. Journal of Economic Survey 15 (5): 589-611.

Gill, D., and V. Prowse. 2011. A novel computerized real effort task based on sliders. Available at SSRN: $\underline{\text { https://ssrn.com/abstract=1732324 or http://dx.doi.org/10.2139/ssrn.1732324. }}$

Gill, D., and V. Prowse. 2012. A structural analysis of disappointment aversion in a real effort competition. The American Economic Review 102 (1): 469-503.

Hannan, R. 2016. Discussion of "Communicated values as informal controls: Promoting quality while undermining productivity?', Contemporary Accounting Research 33 (4): 1435-1439.

Hecht, G., I. Tafkov, and K. Towry 2012. Performance spillover in a multitask environment. Contemporary Accounting Research 29 (2): 563-589.

Henri, J. 2006. Organizational culture and performance measurement systems. Accounting, Organizations and Society 31 (1): 77-103.

Highhouse, S., J. Hoffman, E. Greve, and A. Collins. 2002. Persuasive impact of organizational value statements in a recruitment context. Journal of Applied Social Psychology 32 (8): $1737-1755$.

Holmstrom, B., and Milgrom, P. 1991. Multitask principal-agent analyses: Incentive contracts, asset ownership, and job design. The Journal of Law, Economics, and Organization 7: 24- 
52.

Kachelmeier, S., T. Thornock, and M. Williamson. 2016. Communicated values as informal controls: Promoting quality while undermining productivity? Contemporary Accounting Research 33 (4): 1411-1434.

Lepper, M., and D. Greene. 1978. The Hidden Costs of Reward: New Perspectives on the Psychology of Human Motivation. Hillsdale, NY: Erlbaum.

Libby, R., and M. Lipe. 1992. Incentives, effort, and the cognitive processes involved in accounting-related judgments. Journal of Accounting Research 30 (2): 249-273.

Liu, W. 2017. The Effect of Group Identity on Sabotage Induced by Relative Performance Information. Dissertation, University of Waterloo, Waterloo, Ontario, Canada.

Malmi, T., and D. Brown. 2008. Management control systems as a package-Opportunities, challenges and research directions. Management Accounting Research 19 (4): 287-300.

Norris, G., and B. O'Dwyer. 2004. Motivating socially responsive decision making: The operation of management controls in a socially responsive organization. The British Accounting Review 36 (2): 173-196.

O'Reilly III, C., J. Chatman, and D. Caldwell. 1991. People and organizational culture: A profile comparison approach to assessing person-organization fit. Academy of Management Journal 34 (3): 487-516.

Pratt, J., and P. Beaulieu. 1992. Organizational culture in public accounting: Size, technology, rank, and functional area. Accounting, Organizations and Society 17 (7): 667-684.

Robinson, S., M. Kraatz, and D. Rousseau. 1994. Changing obligations and the psychological contract: A longitudinal study. Academy of Management Journal 37 (1): 137-152.

Smith, C., D. Organ, and J. Near. 1983. Organizational citizenship behavior: Its nature and antecedents. Journal of Applied Psychology 68 (4): 653-663.

Sprinkle, G. 2000. The effect of incentive contracts on learning and performance. Accounting Review 75 (3): 299-326.

Stevens, D. 2019. Social Norms and the Theory of the Firm: A Foundational Approach. Cambridge: Cambridge University Press.

Stevens, D., and A. Thevaranjan. 2010. A moral solution to the moral hazard problem. Accounting, Organizations and Society 35: 125-139.

Tayler, W., and R. Bloomfield. 2011. Norms, conformity, and controls. Journal of Accounting Research 49 (3): 753-790. 
Urbany, J. 2005. Inspiration and cynicism in values statements. Journal of Business Ethics 62 (2): 169-182.

Wenstøp, F., and A. Myrmel. 2006. Structuring organizational value statements. Management Research News 29 (11): 673-683. 
Figure 1

Experimental Procedures

Informed Consent and Overview

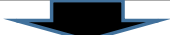

Background, Primer Task Instructions, and Incentive Explanation

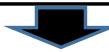

Comprehension Checks

\section{Primer Task}

Slider task with incentive (fixed pay vs. piece-rate) and value statement

(present vs. absent) manipulated; one practice and four paid rounds

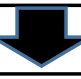

Performance Report and Earnings Information

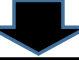

Request to Complete Experimental (Unrewarded) Task
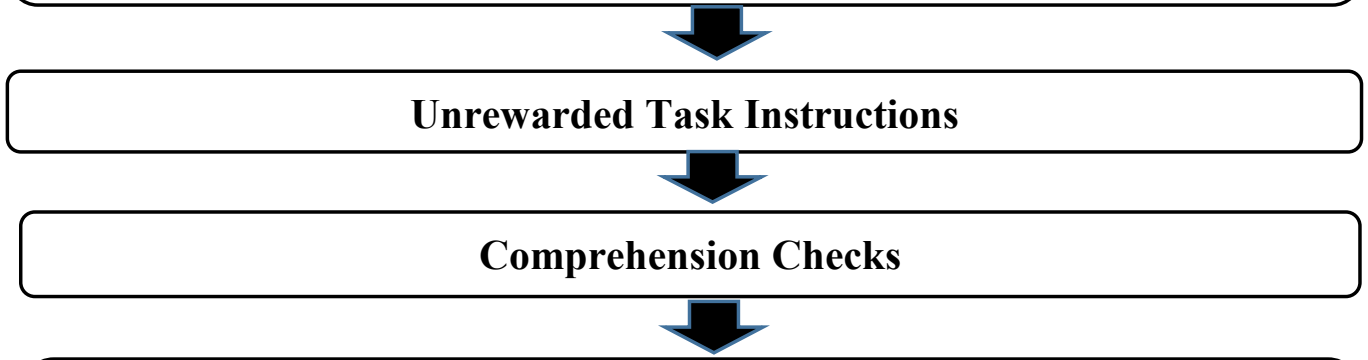

Unrewarded Task

Decoding task; one practice round and four unpaid working rounds

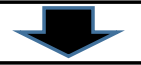

Manipulation Checks

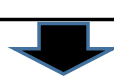

Follow Up Questions and Demographics 
Figure 2

Graphical Representation of Interaction between Incentive Pay and Value Statement from Prior Research

Panel A: Interaction from Primer Task and Reported in Akinyele et al. (2020)

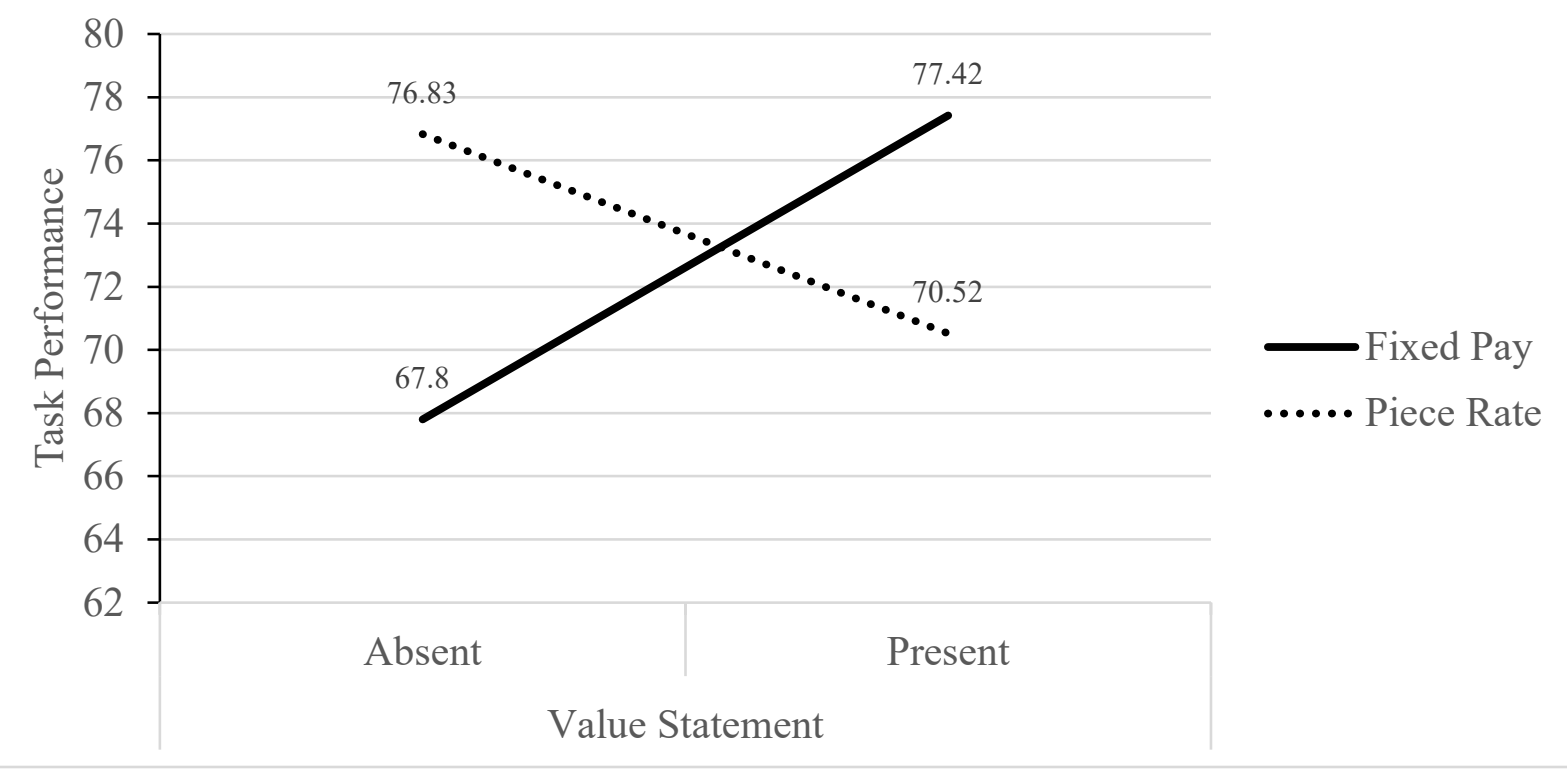

Panel B: Interaction from Kachelmeier et al. 2016

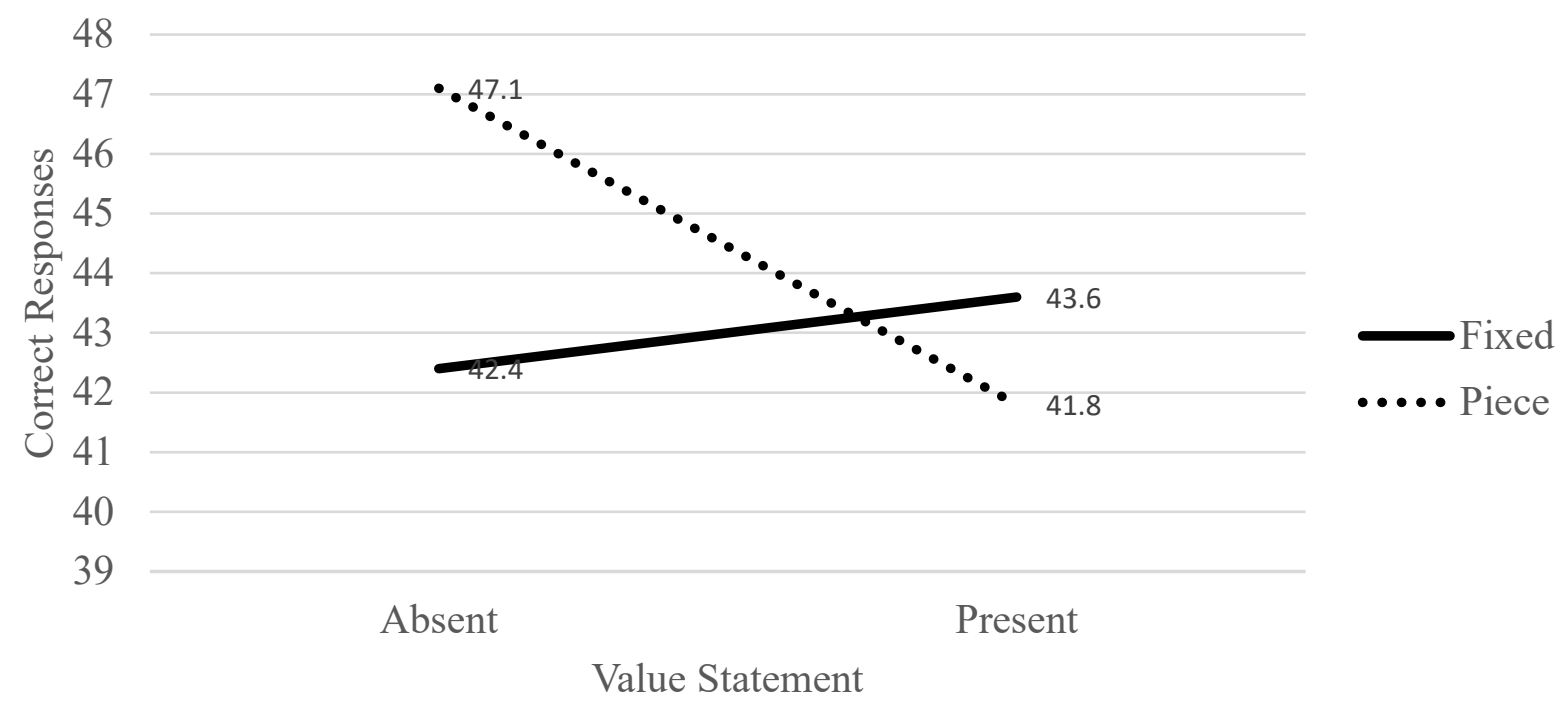


Figure 3

Interaction of Incentive Pay and Value Statement on Unrewarded Task Performance

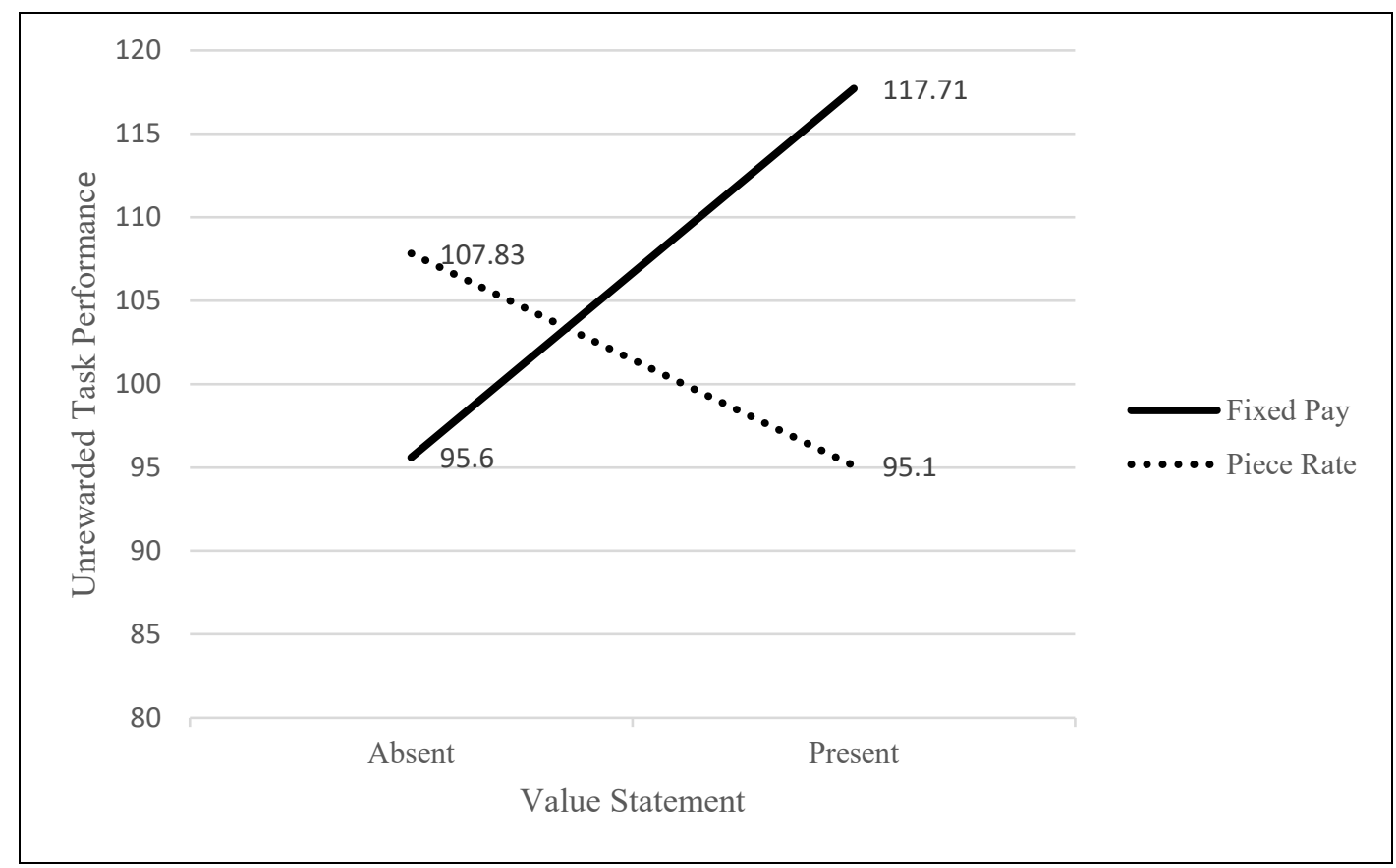

Variable definitions:

Unrewarded task performance is measured as the number of correctly decoded items.

Value statement is manipulated as present or absent.

Incentive pay is manipulated as fixed pay or piece-rate related to effort on the rewarded task. 
Table 1

Unrewarded Task Performance by Experimental Condition

Panel A: Descriptive Statistics - Cell Means (Standard Deviations), Counts

\begin{tabular}{lccc}
\hline \multicolumn{3}{c}{ VALUE STATEMENT } \\
\hline INCENTIVE & Absent & Present & Total \\
\hline Fixed Pay & 95.60 & 117.71 & 107.66 \\
& $(16.90)$ & $(24.61)$ & $(23.96)$ \\
& $n=20$ & $n=24$ & $n=44$ \\
\hline Piece-rate & 107.83 & 95.10 & 101.75 \\
& $(18.42)$ & $(15.57)$ & $(18.10)$ \\
& $n=23$ & $n=21$ & $n=44$ \\
\hline Total & 102.14 & 107.16 & 104.70 \\
& $(18.57)$ & $(23.60)$ & $n=88$ \\
\hline
\end{tabular}

Panel B: ANOVA

\begin{tabular}{lccccc}
\hline \multicolumn{1}{c}{ Source } & $\boldsymbol{S S}$ & $\boldsymbol{d} \boldsymbol{f}$ & $\boldsymbol{M S}$ & $\boldsymbol{F}$ & $\boldsymbol{p}$ \\
\hline Value Statement & 481.15 & 1 & 481.15 & 1.28 & 0.262 \\
\hline Incentive & 590.32 & 1 & 590.32 & 1.57 & 0.214 \\
\hline Value Statement x Incentive & 6641.18 & 1 & 6641.18 & 17.61 & 0.001 \\
\hline Error & 31670.87 & 84 & 377.03 & & \\
\hline
\end{tabular}

Panel C: Simple effects for hypothesis tests on unrewarded task performance

\begin{tabular}{|c|c|c|c|c|c|}
\hline Source & $S S$ & $d f$ & $M S$ & $\boldsymbol{F}$ & $p$ \\
\hline $\begin{array}{l}\text { Fixed Pay } \\
\quad \text { Value Statement Present }>\text { Absent }\end{array}$ & 5332.13 & 1 & 5332.13 & 14.14 & 0.001 \\
\hline $\begin{array}{l}\text { Piece-rate } \\
\quad \text { Value Statement Present }<\text { Absent }\end{array}$ & 1779.14 & 1 & 1779.14 & 4.72 & 0.033 \\
\hline $\begin{array}{l}\text { Value Statement Present } \\
\text { Fixed Pay }>\text { Piece-rate }\end{array}$ & 5727.14 & 1 & 5727.14 & 15.19 & 0.001 \\
\hline $\begin{array}{l}\text { Value Statement Absent } \\
\text { Piece-rate }>\text { Fixed Pay }\end{array}$ & 1599.06 & 1 & 1599.06 & 4.24 & 0.044 \\
\hline \multicolumn{6}{|c|}{ Panel D: Planned contrast test for $\mathrm{H} 2$ on unrewarded task performance } \\
\hline Source & $\begin{array}{l}\text { Value of } \\
\text { contrast }\end{array}$ & $\begin{array}{c}\text { Std. } \\
\text { Error }\end{array}$ & $t$ & $d f$ & $p$ \\
\hline $\begin{array}{l}\text { Fixed Pay } \\
\quad \text { Value Statement Present }>\text { Absent }\end{array}$ & 54.60 & 16.36 & 3.34 & 31.57 & 0.002 \\
\hline
\end{tabular}

Notes: ANOVA p-values are two-tailed, simple effects for hypothesis test p-values are one-tailed.

Variable definitions:

Unrewarded task performance is measured as the number of letters correctly decoded by participants.

Value statement is manipulated as present or absent.

Incentive is manipulated as fixed pay or piece-rate related to the rewarded task. 
Table 2

Unrewarded Task Performance by Experimental Condition (First Two Rounds)

Panel A: Descriptive Statistics - Cell Means (Standard Deviations), Counts

\begin{tabular}{lccc}
\hline \multicolumn{3}{c}{ VALUE STATEMENT } \\
\hline FNCENTIVE & Absent & Present & Total \\
\hline Pixed Pay & 46.85 & 55.63 & 51.64 \\
& $(8.65)$ & $(12.25)$ & $(11.53)$ \\
& $n=20$ & $n=24$ & $n=44$ \\
\hline Total & 52.09 & 46.33 & 49.34 \\
& $(9.04)$ & $(8.16)$ & $(9.01)$ \\
& $n=23$ & $n=21$ & $n=44$ \\
\hline
\end{tabular}

Panel B: ANOVA

\begin{tabular}{lccccc}
\hline \multicolumn{1}{c}{ Source } & $\boldsymbol{S S}$ & $\boldsymbol{d f}$ & $\boldsymbol{M S}$ & $\boldsymbol{F}$ & $\boldsymbol{p}$ \\
\hline Value Statement & 49.95 & 1 & 49.95 & 0.52 & 0.471 \\
\hline Incentive & 89.96 & 1 & 89.96 & 0.94 & 0.334 \\
\hline Value Statement x Incentive & 1154.94 & 1 & 1154.94 & 12.12 & 0.001 \\
\hline Error & 8002.67 & 84 & 95.27 & & \\
\hline
\end{tabular}

Panel C: Simple effects for hypothesis tests on unrewarded task performance

\begin{tabular}{lccccc}
\hline \multicolumn{1}{c}{ Source } & $\boldsymbol{S S}$ & $\boldsymbol{d f}$ & $\boldsymbol{M S}$ & $\boldsymbol{F}$ & $\boldsymbol{p}$ \\
\hline $\begin{array}{l}\text { Fixed Pay } \\
\quad \text { Value Statement Present > Absent }\end{array}$ & 840.01 & 1 & 840.01 & 8.82 & 0.004 \\
\hline $\begin{array}{l}\text { Piece-rate } \\
\quad \text { Value Statement Present < Absent }\end{array}$ & 363.39 & 1 & 363.39 & 3.81 & 0.054 \\
\hline $\begin{array}{l}\text { Value Statement Present } \\
\text { Fixed Pay > Piece-rate }\end{array}$ & 966.95 & 1 & 966.95 & 10.15 & 0.002 \\
\hline $\begin{array}{l}\text { Value Statement Absent } \\
\text { Piece-rate > Fixed Pay }\end{array}$ & 293.39 & 1 & 293.39 & 3.08 & 0.083 \\
\hline
\end{tabular}

Panel D: Planned contrast test for $\mathrm{H} 2$ on unrewarded task performance

\begin{tabular}{lccccc}
\hline \multicolumn{1}{c}{ Source } & $\begin{array}{c}\text { Value of } \\
\text { Contrast }\end{array}$ & $\begin{array}{c}\text { Std. } \\
\text { Error }\end{array}$ & $\boldsymbol{t}$ & $\boldsymbol{d f}$. & $\boldsymbol{p}$ \\
\hline $\begin{array}{l}\text { Fixed Pay/Value Statement Present } \\
\text { > All other conditions }\end{array}$ & 21.60 & 7.01 & 3.08 & 84 & 0.003 \\
\hline
\end{tabular}

Notes: ANOVA p-values are two-tailed, simple effects for hypothesis test $\mathrm{p}$-values are one-tailed.

Variable definitions:

Unrewarded task performance is measured as the number of letters correctly decoded by participants.

Value statement is manipulated as present or absent.

Incentive is manipulated as fixed pay or piece-rate related to the rewarded task. 
Table 3

Unrewarded Task Performance by Experimental Condition (Last Two Rounds)

Panel A: Descriptive Statistics - Cell Means (Standard Deviations), Counts

\begin{tabular}{lccc}
\hline \multicolumn{3}{c}{ VALUE STATEMENT } \\
\hline FNCENTIVE & Absent & Present & Total \\
\hline Piece-rate & 48.75 & 62.08 & 56.02 \\
& $(8.67)$ & $(12.64)$ & $(12.80)$ \\
& $n=20$ & $n=24$ & $n=44$ \\
\hline Total & 55.74 & 48.76 & 52.41 \\
& $(10.17)$ & $(8.10)$ & $(9.79)$ \\
& $n=23$ & $n=21$ & $n=44$ \\
\hline
\end{tabular}

Panel B: ANOVA

\begin{tabular}{lccccc}
\hline \multicolumn{1}{c}{ Source } & $\boldsymbol{S S}$ & $\boldsymbol{d} \boldsymbol{f}$ & $\boldsymbol{M S}$ & $\boldsymbol{F}$ & $\boldsymbol{p}$ \\
\hline Value Statement & 221.05 & 1 & 221.05 & 2.14 & 0.148 \\
\hline Incentive & 219.40 & 1 & 219.40 & 2.12 & 0.149 \\
\hline Value Statement x Incentive & 2257.11 & 1 & 2257.11 & 21.81 & 0.001 \\
\hline Error & 8691.83 & 84 & 103.47 & & \\
\hline
\end{tabular}

Panel C: Simple effects for hypothesis tests on unrewarded task performance

\begin{tabular}{lccccc}
\hline \multicolumn{1}{c}{ Source } & $\boldsymbol{S S}$ & $\boldsymbol{d f}$ & $\boldsymbol{M S}$ & $\boldsymbol{F}$ & $\boldsymbol{p}$ \\
\hline $\begin{array}{l}\text { Fixed Pay } \\
\quad \text { Value Statement Present > Absent }\end{array}$ & 1939.39 & 1 & 1939.39 & 18.74 & 0.001 \\
\hline $\begin{array}{l}\text { Piece-rate } \\
\quad \text { Value Statement Present < Absent }\end{array}$ & 534.39 & 1 & 534.39 & 5.16 & 0.026 \\
\hline $\begin{array}{l}\text { Value Statement Present } \\
\text { Fixed Pay > Piece-rate }\end{array}$ & 1987.56 & 1 & 1987.56 & 19.21 & 0.001 \\
\hline $\begin{array}{l}\text { Value Statement Absent } \\
\text { Piece-rate > Fixed Pay }\end{array}$ & 522.56 & 1 & 522.56 & 5.05 & 0.027 \\
\hline
\end{tabular}

Panel D: Planned contrast test for $\mathrm{H} 2$ on unrewarded task performance

\begin{tabular}{lccccc}
\hline \multicolumn{1}{c}{ Source } & $\begin{array}{c}\text { Value of } \\
\text { Contrast }\end{array}$ & $\begin{array}{c}\text { Std. } \\
\text { Error }\end{array}$ & $\boldsymbol{t}$ & $\boldsymbol{d f}$. & $\boldsymbol{p}$ \\
\hline $\begin{array}{l}\text { Fixed Pay/Value Statement Present } \\
\text { > All other conditions }\end{array}$ & 33.00 & 8.44 & 3.91 & 32.13 & 0.001 \\
\hline
\end{tabular}

Notes: ANOVA p-values are two-tailed, simple effects for hypothesis test $\mathrm{p}$-values are one-tailed.

Variable definitions:

Unrewarded task performance is measured as the number of letters correctly decoded by participants.

Value statement is manipulated as present or absent.

Incentive is manipulated as fixed pay or piece-rate related to the rewarded task. 